\title{
Modelling of Ship Collision Frequency in The Strait of Malacca and Singapore (SOMS) Influenced by Indonesian Port Development
}

\author{
Dhimas W. Handani, ${ }^{1,2, a}$, I Made Ariana ${ }^{1,2}$, A.A.B. Dinariyana ${ }^{1,2}$, \\ and I.G.M. Sukanegara Adhita ${ }^{2}$ \\ ${ }^{1}$ Department of Marine Engineering, Institut Teknologi Sepuluh Nopember, Surabaya, Indonesia \\ ${ }^{2}$ PUI Keselamatan Kapal dan Instalasi Laut, Institut Teknologi Sepuluh Nopember, Surabaya, \\ Indonesia \\ a.dhimas@ne.its.ac.id
}

Keywords: $\quad$ Ship collision, modelling, SOMS, IWRAP.

Abstract: The Strait of Malacca and Singapore (SOMS) is one of the busiest shipping channel lies between sea water territory of Indonesia, Singapore and Malaysia. The strait becomes a very important part of world freight transportation since it connects the shipping lane between East Asia, West Asia, Australia and Europe. Even though Traffic Separation Scheme (TSS) has been applied in the area to prevent the unlikely event of vessel collision, the number of catastrophic ship accident tends to increase by year. The Indonesian government plans to develop the ports located around SOMS. Such development increases the number of ships call per year which causes the ship traffic density in SOMS becomes more crowdy. This paper conducts an analysis on the vessel collision frequency influenced by the Indonesian ports development around waterway of SOMS including ports in Tanjung Pinang, Dumai and Batam Island. IALA Waterways Risk Assessment Program (IWRAP) is utilized to determine the annual frequency of head-on collision, overtaking collision and crossing collision. The Result of IWRAP modeling in this study shows that there is a significant increase of the future total ship collision frequency. The crossing collision contribute the most for the annual vessel collision, since there are higher number of ships cross the TSS caused by the development of Indonesian port around SOMS.

\section{Introduction}

\subsection{Overview of The Straits of Malacca and Singapore (SOMS)}

The transportation of goods using ship between East Asia, European Union, and Middle East country has been taken place for such long time ago influenced by the world's trading, including Chinese, Japanese and South Korean industry, Indonesian spices, Middle East oil production etc. The transportation of these commodity takes the shortest route if the fleet uses The Strait of Malacca and Singapore (SOMS). The channel plays a significant role for the world's transportation of goods which includes crude and product oil, bulk and containers. This shipping channel is very important since 
this is the only one option if the shipping company considers to gain more profit by reducing the sailing time of their ship. Without this channel, all fleet desiring to pass through needs to reroute inside the Indonesian archipelago. This would increase the sailing time around three days [1]. SOMS is located in the three water territory, Indonesia, Singapore and Malaysia. It connects the international shipping traffic between the Indian Ocean and the Pacific Ocean and between the littoral countries.

SOMS is one of the busiest shipping channel in the world. The international shipping passing through SOMS involves large size of ship, while there are also ship traffic that crossing the international lane connecting Indonesia, Malaysia and Singapore. The type of the crossing ships is mainly fast passenger boat. With the geographical condition of SOMS which has some narrow and shallow water, the safety of navigation becomes the most critical issue. In some part, the strait is narrow down to $2.8 \mathrm{~km}$, while the channel is $2.1 \mathrm{~km}$ at this point. The ship traffic density in SOMS is high. It reaches around 300 ships passing through the channel per day with one ship arrival/ departure in every 2-3 minutes. Annually, there could be more than 100.000 vessels within this strait [1], [2]. This condition makes SOMS becomes the bottleneck of ship traffic connecting major world trade good's involving 600 ports in 120 countries [3].

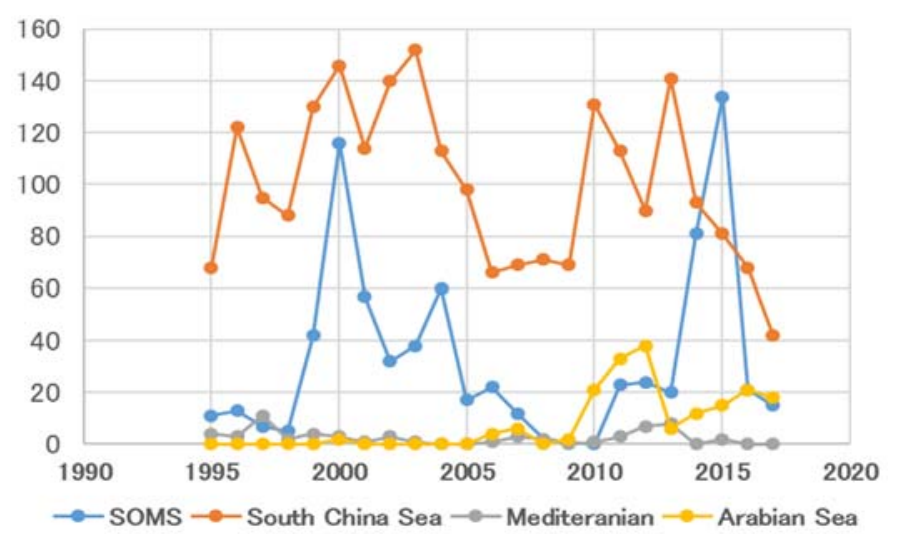

Figure 1: History of ship collision in some water territory

The number of vessel collision in SOMS is higher than that of other areas except in South China Sea, based on Figure 1. Viewed from the location of the accident, territory waters become the location with the highest accident rate. There is $40 \%$ of the total vessel accident was occurred in this territory. While the second rank is occupied by international waters and accidents in the harbor area which have $38 \%$ and $22 \%$ respectively which is shown in Figure 2. This report indicates that vessel accident is frequently occurred the most in the international and territory water area which mostly cover the main international shipping lane in SOMS. The unlikely event of collision of vessel in this area has also cause a huge loss especially casualties on people. Figure 3 shows the type of casualties caused by incident in SOMS. The incident causes live lost, wounded crew, missing crew, crew hostage and assaulted which their occurrence are 3\%, 10\%, 12\%, 39\% and 36\% respectively. This loss is not only caused by vessel collision but also piracy attack and hijacking.

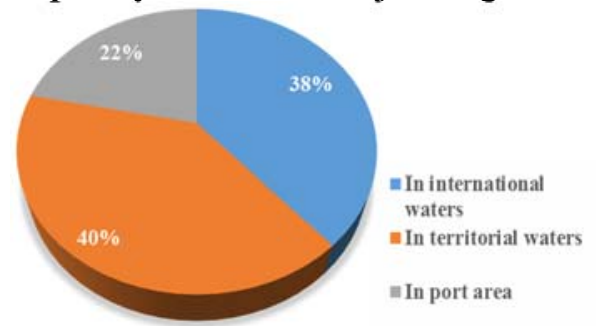

Figure 2: Location of ship collision in SOMS 


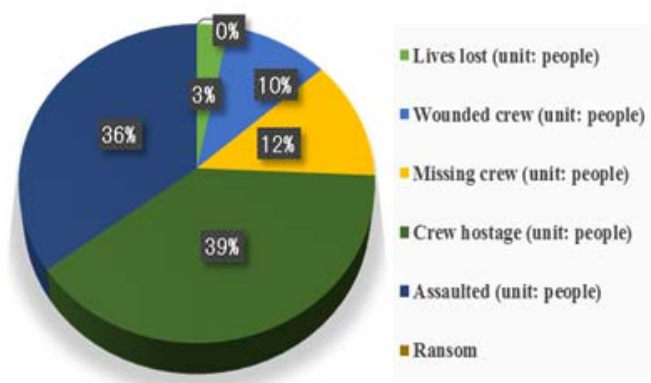

Figure 3: Casualties caused by incident in SOMS

The ship traffic accident that has been recorded in SOMS indicates that this shipping waterway has a high risk of ship collision. In order to reduce the number of unlikely event of ship collision and to manage the ship traffic in waterway, an effort of collision avoidance should be seriously proposed. The Traffic Separation Scheme (TSS) has been established and approved by International Maritime Organization (IMO) as a means of traffic safety management in SOMS. The TSS is a routing measure which separate the two opposing shipping lane by using a separation line or zone. The opposing waterway in SOMS is separated by means of zone in order to avoid the shipping lane from anchorage area, dangerous location because of wreck or shallow water etc. The TSS has been a mandatorily established since 1981 [4]. Since then, the two-way route of waterway in SOMS has been separated, increasing the safety of ship navigation because the two opposing routes are separated avoiding direct encounter between ship.

In 1998, IMO has also established a mandatory ship reporting system in the SOMS. The mandatory ship reporting system in the Straits of Malacca and Singapore is called as STRAITREP. This mandatory system makes all vessel aimed to passing through the strait have to report to the authority before they enter and leave the waterway in SOMS. The STRAITREP was proposed by the three countries which have a sea water territory in this strait, i.e. Indonesia, Singapore and Malaysia. The STRAITREP separate the area of SOMS into 9 sectors. This is aimed to increase the safety of ship navigation and make easier to monitor the ship movement. All the ship entering the waterway will be managed by the communication between the ship operator and the Vessel Traffic Service (VTS). The mandatory ship report should be done to the Singapore VTS when the ship is in sector 7-9. While the sector 1-5 and sector 6 are under the authority of VTS Klang and VTS Johor in Malaysia [1] [4]. The recorded data of the number of ship which carried out a mandatory report to VTS in recent years in SOMS has been collected. Fig. 4 shows the data of the number of ship starting from 2006 until 2016. From this figure, we could see that in average, the number of ship passing through the SOMS is increased.

The number of ship transit in SOMS increases year by year. This is strongly influenced by the international trading and the economic growth of the littoral country (Indonesia, Singapore and Malaysia). Especially, the Indonesian government plan to accelerate the development of Indonesian border including water territory which covers some area in SOMS. The Indonesian government attempts to develop some international port near the Straits of Malacca and Singapore, such as port of Tanjung Pinang. The future ship collision frequency may increase when the development of some Indonesian port has been completed since the number of ship transit is increased. Moreover, the traffic density in SOMS in the future is not only significantly influenced by the development plan of new international port in the port of Tanjung Pinang but also influenced by the existing port which is going to increase the number of ship's call in the future. Other Indonesian port which influence the ship traffic density in SOMS are Port of Dumai and some ports located in the Batam Island. It is important to analyze the ship collision frequency in order to know how is the estimation of the vessel collision in the future. 


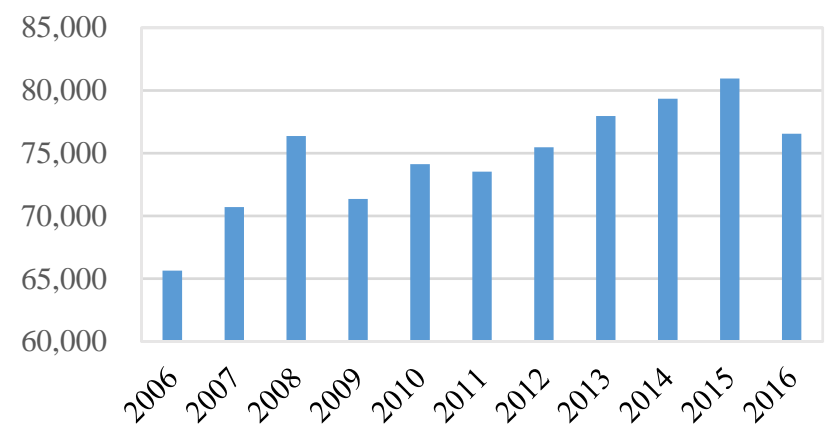

Figure 4: Number of ships which report to the STRAITREP

This paper deal with important issue to know how is the ship collision frequency in the future influenced by Indonesian port development, since this could be as a consideration for the authority to establish a new regulation for enhancing the safety of navigations and reducing the frequency of vessel collision in the SOMS. In order to do ship collision frequency analysis, some method has been appeared in the some researches. One tool that is adopted by IALA (International Association of Marine Aids to Navigation and Lighthouse Authorities) is IWRAP (IALA Waterway Risk Assessment Program). IWRAP is a modeling tool of maritime waterway for estimating the frequency of collision between vessels and grounding in a shipping lane with the inputted data such as the ship traffic density, detail of ship type, size and speed which involve in the waterway, shipping lane geometry and bathymetry [5]. This paper utilizes this tool for analyzing the vessel collision including head on, over taking and crossing collision if vessel in SOMS.

\subsection{Ship Traffic Collision History in SOMS}

Based on historical data, SOMS is a shipping channel which has a relatively high number of accidents. Fig. 1 shows the accident data in several places such as SOMS, South China Sea, Mediterranean Sea and Arabian Sea. This figure depicts the event of collisions between vessels recorded from year 1995 until 2017. We could see that SOMS has a relatively high accident rate compared to other shipping areas. According to these data, accidents in the SOMS area occur at the highest reached 130 times in one year that occurred in 2015. The highest number of ship accident was occurred in 2015, followed by that was occurred in 2000 which reached 115 times event of accident. The comparison of number of accidents occurred in SOMS and other places recorded from 1995 to 2017 can be seen in the Fig. 1 bellow. The high annual vessel collision in this area has attract a great attention from maritime authority, since SOMS has a great impact on the global economy if there is a problem which makes the vessel unable to pass through the channel such as traffic congestion, marine collision. Such event induces a great cost for global logistic industry [3].

\section{Ship Collision Modelling}

\subsection{Method of Ship Collision Modelling}

There has been such a long term research development of ship collision modelling for ship's navigation in waterway. This part of paper discusses some methods that have been proposed to analyze the frequency of ship collision. It is common to write $\lambda_{c o l}$, to indicate the frequency of collision between ships which the value is the product of accident candidate $\left(N_{C}\right)$ and the causation factor $\left(P_{C}\right)$. Accident candidate is the number of ship under a critical situation in a course which leads 
to an event of collision. The causation factor is the probability of the vessel unable to make a maneuver effort to avoid the collision. This mathematical model was firstly proposed by [6], [7] and [8]. The mathematical modelling is expressed as in (1).

$$
\lambda_{\text {col }}=N_{C} \cdot P_{C}
$$

This model is known as Fujii model which propose the model of ship collision by determining the diameter of collision geometry which can be calculated based on ship principal dimensions, ship speed and angle of crossing course between vessels. This proposed method is only applicable for crossing collision [9]. Further development of ship collision modelling was proposed by [10]. This model is known as Pedersens model which improves the previous geometry of collision diameter. The ships involved in the model are grouped based on their type and size of principal dimension. The IALA Waterway Risk Assessment Program is based on this model. IWRAP software allows us to analyze the frequency of ship collision by using data of ship traffic in a waterway by grouping the ship type and size. This software also compatible for data received from the receiver of Automatic Identification System (AIS).

Some approach of ship collision modelling was done by using ship domain theory. A work on crossing situation, has been proposed by [11] which considers a fix distance of critical situation between ships. The critical situation is determined as a situation when the distance between encounter ships is $0.5 \mathrm{Nm}$. This value is fix independent of the crossing angle between ships and ship manoeuvrability. Another static model also were proposed by [12] and [13]. In other development, the well-known model proposed by [7] was more evaluated by replacing the diameter of collision geometry with a minimum distance of collision (MDTC). The geometrical probability introduced in this model is influenced by the vessel traffic data in the waterway, vessel dynamics and the capability of vessel to maneuver in order to avoid the collision [14] [15].

\subsection{IWRAP Modelling for Ship Collision Analysis}

The modelling of ship collision in a waterway by using IWRAP is discussed in this part of this paper. The number of collision candidate between two ships $i$ and $j$ with the sailing direction of (1) and (2) respectively, in a pathway with length of $\mathrm{L}$ is expressed as in equation (2). Where $V_{i}^{(1)}$ is the speed of ship type $i$ in direction (1), $V_{j}^{(2)}$ is the speed of ship type $\mathrm{j}$ in direction (2), $V_{i j}$ is the relative speed of two ships which is derived from the summation of $V_{i}^{(1)}$ and $V_{j}^{(2)}, Q_{i}^{(1)}$ and $Q_{j}^{(2)}$ is the number of passages per unit time for ship type $i$ and $j$ in direction of (1) and (2) respectively.

$$
N_{C}=L \sum_{i j} P_{i j} \frac{V_{i j}}{V_{i}^{(1)} V_{j}^{(2)}} Q_{i}^{(1)} Q_{j}^{(2)}
$$

The probability of the event of head on collision between two ships depends on the distribution of ship traffic in the waterway and is expressed as (3).

$$
\begin{aligned}
P_{i j} & =P\left[y_{i}^{(1)}+y_{j}^{(2)}<B_{i j}\right]-P\left[-y_{i}^{(1)}-y_{i}^{(2)}>B_{i j}\right] \\
& =\int_{-\infty}^{\infty} f_{Y_{i}}\left[F_{Y_{j}}\left(-y_{i}+B_{i j}\right)-F_{Y_{j}}\left(-\left(Y_{i}+B_{i j}\right)\right)\right] d_{i j}
\end{aligned}
$$

$B_{i j}$ is the breadth average of the two vessels, $y_{i}$ and $y_{j}$ are the distance of the center path of the ships type $i$ and $j$ respectively, to the axis route, $f_{Y_{i}}$ and $f_{Y_{j}}$ are the distribution function of the ship traffic spreads on the route which both distribution have to be assumed independent. The distribution 
of ship traffic on the route may use any type distribution, even though in many previous publication, they were assumed by using normal distribution. In the case of normal distribution, the probability of two vessel collision without any evasive effort to maneuvers is expressed as in (1). Where $\Phi$ is the function of the standard normal distribution with $\left(\mu_{i}, \sigma_{i}\right)$ and $\left(\sigma_{j}, \mu_{j}\right)$ as distribution parameter for traffic lane (1) and (2) respectively.

$$
P_{i j}=\Phi\left(\frac{B_{i j}-\mu_{i j}}{\sigma_{i j}}\right)-\Phi\left(-\frac{B_{i j}-\mu_{i j}}{\sigma_{i j}}\right)
$$

The mean sailing distance between vessels which have heading in opposite direction is expressed as $\mu_{i j}=\mu_{i}^{(1)}+\mu_{j}^{(2)}$, while the standard deviation of the joint distribution is $\sigma_{i j}=\sqrt{\left(\sigma_{i}^{(1)}\right)^{2}+\left(\sigma_{j}^{(2)}\right)^{2}}$.

Overtaking collision can be occurred when $V_{i j}>0$, otherwise overtaking will never be occurred. In this case, it could be expressed as $V_{i j}=V_{i}^{(1)}-V_{j}^{(2)}$ and the mean sailing distance between vessel is $\mu_{i j}=\mu_{i}^{(1)}-\mu_{j}^{(2)}$. The geometric probability of overtaking is expressed in (2).

$$
\begin{aligned}
P_{i j} & =P\left[y_{i}^{(1)}-y_{i}^{(2)}<B_{i j}\right]-P\left[-y_{i}^{(1)}+y_{j}^{(2)}>B_{i j}\right] \\
& =\int_{-\infty}^{\infty} f_{Y_{i}}\left[F_{Y_{j}}\left(y_{i}+B_{i j}\right)-F_{Y_{j}}\left(-\left(B_{i j}-y_{i}\right)\right)\right] d_{y_{j}}
\end{aligned}
$$

IWRAP adopts Pedersens model [10] for relative speed of ships and geometric collision diameter. The number of collision candidate is expressed as in (3) [16].

$$
N_{C}=\sum_{i, j} \frac{Q_{i}^{(1)} Q_{j}^{(2)}}{V_{i}^{(1)} V_{j}^{(2)}} D_{i j} V_{i j} \frac{1}{\sin \theta}, \theta \neq 0
$$

Other variable in determining frequency of collision is the causation factor. The value of causation factor used by IWRAP for head on, overtaking and crossing collision are $0.5 \times 10^{-4}, 1.1 \times 10^{-4}$ and $1.3 \times 10^{-4}$ respectively [17].

\section{Ship Collision Modelling}

This paper proposes a model of ship traffic using IWRAP to calculate the vessel collision frequency in SOMS influenced by the traffic density of Indonesian port development around this area. There are three area of port development which are modelled in this paper, they are Ports in Batam Island, Port of Dumai and Port of Tanjung Pinang. The ship traffic to these ports enters the TSS in Malacca and Singapore Strait which increase the traffic density in this area. The TSS and ship reporting system in SOMS can be seen in Figure 5, where the ship passage have to obey the rule during voyage. The TSS separate the opposite traffic into two separate lane by using some separation area/line. The application of TSS since 1981 in SOMS is aimed to reduce the event of ship collision, especially head on collision because of traffic opposite direction. The natural traffic of vessel in SOMS can be seen in Figure 6. This density map shows the traffic density in SOMS during 2016. From this figure we can see that mainly the ships course is in the TSS. The natural ship density is very high. It is indicated by the dark color of the density map. Many of them crosses the strait, especially traffic of fast passenger ship from/to Batam Island - Singapore. This condition causes the probability of ship collision increases as well as the frequency of ship collision. 
The high density of ship traffic in SOMS correlate with the number of collision which has been shown in Figure 4. The higher density of ship traffic effects on the higher probability of ship collision. The model developed in this paper is not only consider the traffic density in the current year but also calculates the future traffic density influenced by the development of Indonesian port. The model developed in this paper evaluate three types of collision. The type of collision under evaluation are head on, overtaking and crossing collision. This paper utilizes IWRAP Mk2 software for modelling ship collision in SOMS. This software uses tool named as LEG for modelling the traffic lane and Way Point to model the crossing point between two or more traffic lane. The IWRAP model for ship traffic in SOMS is shown in Figure 7. The model is comprised of LEG and Way Point which considers the TSS and natural traffic of SOMS shown in Figure 5 and Figure 6 respectively. This model includes the area around three main ports under case study, i.e. Ports in Batam Island, Port of Dumai and Port of Tanjung pinang.

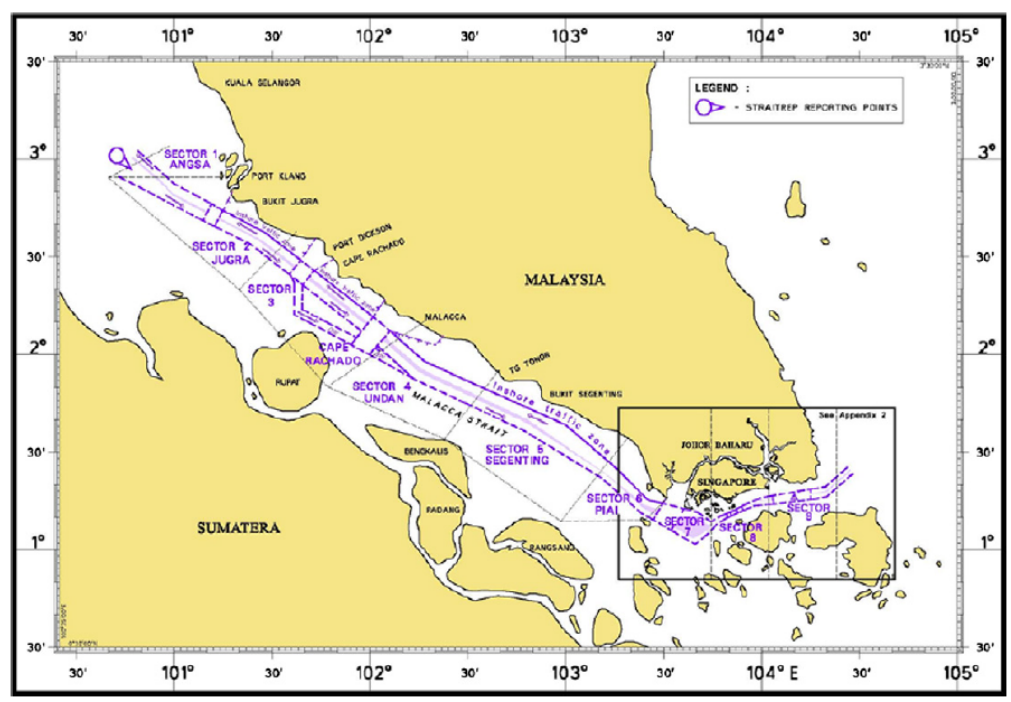

Figure 5: Design of TSS and reporting system (STRAITREP) in SOMS [1]

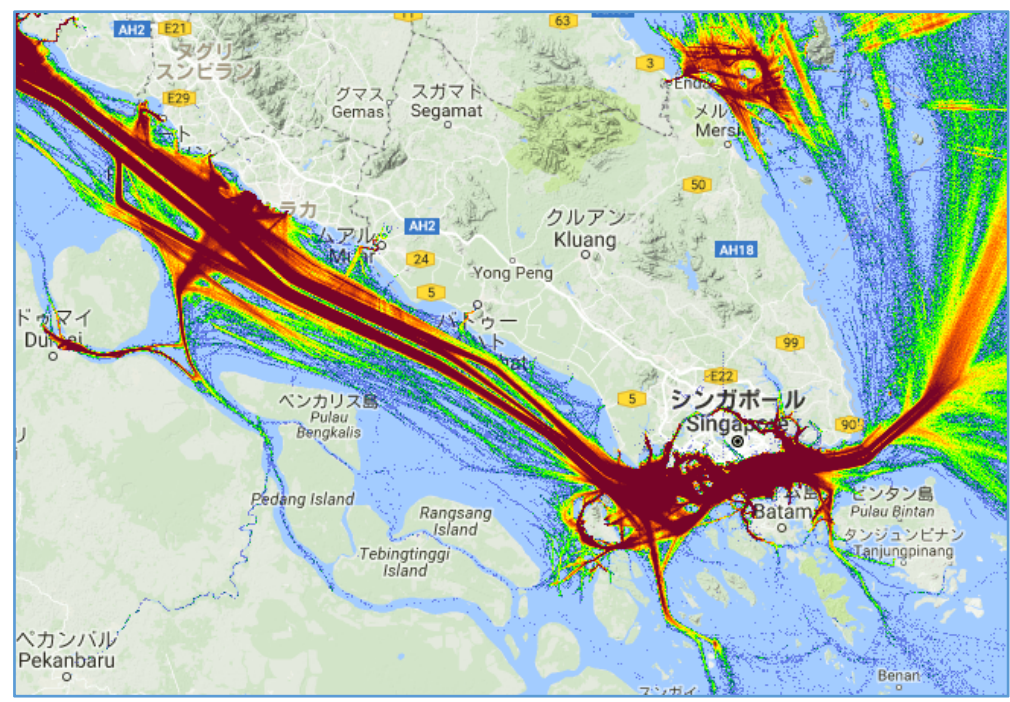

Figure 6: Natural ship traffic density in SOMS [18] 


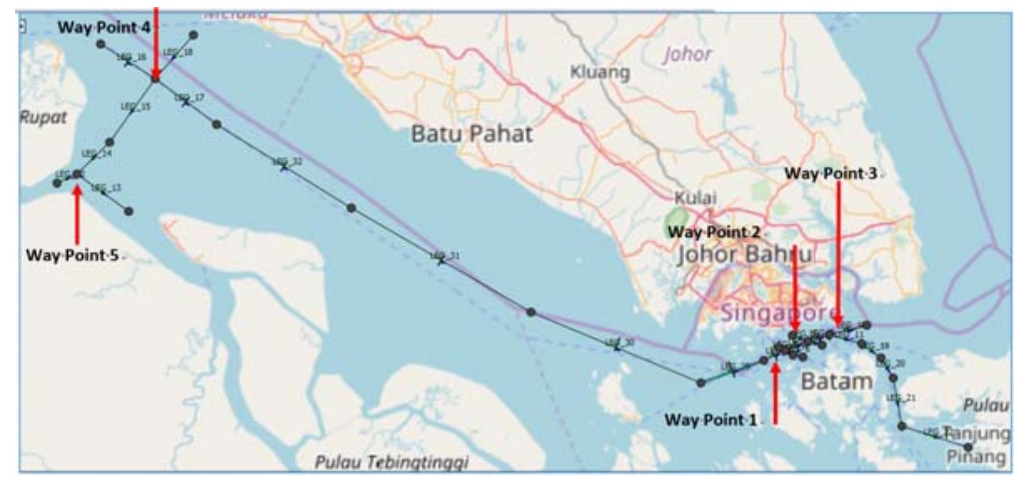

Figure 7: IWRAP model showing location of Waypoint and LEG

The data of Automatic Identification System (AIS) could be used as input for IWRAP if available. In this paper, data of inbound and outbound of ship to the Port of Dumai, Tanjung Pinang and Batam Island has been collected during 2016. These data is inputted into IWRAP Mk2 model such as shown in Figure 7. The model in this paper uses data which manually inputs the number, type, speed and length of ship into the LEG and Way Point in IWRAP model to calculate the frequency of collision.

\section{Result and Analysis}

This paper utilizes an IALA Waterway Risk Assessment Program (IWRAP) to construct a model of ship traffic density in the SOMS and calculate the frequency of vessel collision. The data of ship traffic of three main locations in Indonesian territory as source of ship traffic, which influence the traffic density in SOMS, has been collected in 2016. This data is ship call in three main port, i.e. Port of Dumai, Batam and Tanjung Pinang. The IWRAP Mk2 is used in the modelling process which employs LEG and Way Point for inputting data of ship traffic, including ship type, length, speed and density. The model that has been constructed could be seen in Figure 7 which shows the LEG and Way Point for design of traffic lane, interpreting the separated ship traffic lane as in the TSS, and the crossing point where the ships from Indonesia territory cross the strait toward Singapore/Malaysia or contrary. This design of model comprises of 22 LEGs, and 5 Way Points. It can be seen in Figure 7 that there are 8 LEGs (LEG 1-8) and 2 Way Points (WP 1 and 2) in the model of ship traffic around Batam Island.

Table 1: Collision Frequency of Ship Traffic in Batam

\begin{tabular}{|c|c|c|c|c|c|c|c|c|}
\hline \multicolumn{3}{|c|}{ Head On } & \multicolumn{4}{c|}{ Crossing } & \multicolumn{3}{c|}{ Overtaking } \\
\hline \multirow{2}{*}{$\mathbf{L}$} & \multicolumn{2}{|c|}{ Frequency } & \multirow{2}{*}{$\mathbf{W}$} & \multicolumn{2}{c|}{ Frequency } & \multirow{2}{*}{$\mathbf{L}$} & \multicolumn{2}{c|}{ Frequency } \\
\cline { 2 - 3 } & Now & Future & $\mathbf{P}$ & Now & Future & & Now & Future \\
\hline $\mathbf{1}$ & $7.6 \mathrm{E}-21$ & $2.5 \mathrm{E}-20$ & $\mathbf{1}$ & 0.07 & 0.240 & $\mathbf{1}$ & $3.0 \mathrm{E}-02$ & $9.6 \mathrm{E}-02$ \\
\hline $\mathbf{2}$ & $7.9 \mathrm{E}-21$ & $2.6 \mathrm{E}-20$ & $\mathbf{2}$ & 0.03 & 0.126 & $\mathbf{2}$ & $3.1 \mathrm{E}-02$ & $1.0 \mathrm{E}-01$ \\
\hline $\mathbf{3}$ & $7.3 \mathrm{E}-21$ & $2.4 \mathrm{E}-20$ & & & & $\mathbf{3}$ & $2.8 \mathrm{E}-02$ & $9.2 \mathrm{E}-02$ \\
\hline $\mathbf{4}$ & $5.9 \mathrm{E}-05$ & $1.9 \mathrm{E}-04$ & & & & $\mathbf{4}$ & $6.7 \mathrm{E}-08$ & $2.4 \mathrm{E}-07$ \\
\hline $\mathbf{5}$ & $6.8 \mathrm{E}-05$ & $2.2 \mathrm{E}-04$ & & & & $\mathbf{5}$ & $7.7 \mathrm{E}-08$ & $5.5 \mathrm{E}-07$ \\
\hline
\end{tabular}




\begin{tabular}{|c|c|c|c|c|c|c|c|c|}
\hline \multicolumn{2}{|c|}{ Head On } & \multicolumn{3}{c|}{ Crossing } & \multicolumn{3}{c|}{ Overtaking } \\
\hline \multirow{2}{*}{ L } & \multicolumn{2}{|c|}{ Frequency } & \multirow{2}{*}{ W } & \multicolumn{2}{c|}{ Frequency } & \multirow{2}{*}{ L } & \multicolumn{2}{c|}{ Frequency } \\
\cline { 2 - 6 } \cline { 7 - 9 } & Now & Future & $\mathbf{P}$ & Now & Future & & Now & Future \\
\hline $\mathbf{6}$ & $6.3 \mathrm{E}-04$ & $2.1 \mathrm{E}-03$ & & & & $\mathbf{6}$ & $1.3 \mathrm{E}-04$ & $4.2 \mathrm{E}-04$ \\
\hline $\mathbf{7}$ & $1.8 \mathrm{E}-04$ & $5.8 \mathrm{E}-04$ & & & & $\mathbf{7}$ & $4.2 \mathrm{E}-05$ & $1.4 \mathrm{E}-04$ \\
\hline $\mathbf{8}$ & $2.5 \mathrm{E}-04$ & $4.7 \mathrm{E}-04$ & & & & $\mathbf{8}$ & $5.0 \mathrm{E}-05$ & $1.1 \mathrm{E}-04$ \\
\hline
\end{tabular}

Table 2: Collision Frequency of Ship Traffic in Port of Dumai

\begin{tabular}{|c|c|c|c|c|c|c|c|c|}
\hline \multicolumn{3}{|c|}{ Head On } & \multicolumn{3}{|c|}{ Crossing } & \multicolumn{3}{|c|}{ Overtaking } \\
\hline \multirow{2}{*}{$\mathbf{L}$} & \multicolumn{2}{|c|}{ Frequency } & \multirow{2}{*}{$\begin{array}{l}\mathbf{W} \\
\mathbf{P}\end{array}$} & \multicolumn{2}{|c|}{ Frequency } & \multirow{2}{*}{$\mathbf{L}$} & \multicolumn{2}{|c|}{ Frequency } \\
\hline & Now & Future & & Now & Future & & Now & Future \\
\hline 12 & 5.1E-03 & 1.7E-02 & 4 & 7.5E-03 & 2.5E-02 & 12 & 8.0E-04 & 2.6E-03 \\
\hline 13 & 2.4E-04 & 7.8E-04 & 5 & 3.0E-04 & 9.9E-04 & 13 & 4.9E-05 & 1.6E-04 \\
\hline 14 & 7.6E-03 & 2.5E-02 & & & & 14 & 1.3E-03 & 4.1E-03 \\
\hline 15 & 1.3E-02 & 4.2E-02 & & & & 15 & 2.2E-03 & 7.1E-03 \\
\hline 16 & 2.6E-20 & 8.3E-20 & & & & 16 & $1.7 \mathrm{E}-01$ & 5.5E-01 \\
\hline 17 & $3.1 \mathrm{E}-20$ & 9.9E-20 & & & & 17 & $1.0 \mathrm{E}-01$ & 3.3E-01 \\
\hline 18 & $9.1 \mathrm{E}-05$ & 2.9E-04 & & & & 18 & 2.0E-05 & 6.4E-05 \\
\hline
\end{tabular}

Table 3: Collision Frequency of Ship Traffic in Port of Tanjung Pinang

\begin{tabular}{|c|c|c|c|c|c|c|c|c|}
\hline \multicolumn{3}{|c|}{ Head On } & \multicolumn{3}{c|}{ Crossing } & \multicolumn{3}{c|}{ Overtaking } \\
\hline \multirow{2}{*}{$\mathbf{L}$} & \multicolumn{2}{|c|}{ Frequency } & \multirow{2}{*}{$\mathbf{W}$} & \multicolumn{2}{c|}{ Frequency } & \multirow{2}{*}{$\mathbf{L}$} & \multicolumn{2}{c|}{ Frequency } \\
\cline { 2 - 6 } \cline { 8 - 10 } & Now & Future & $\mathbf{P}$ & Now & Future & & Now & Future \\
\hline $\mathbf{1 1}$ & $7.6 \mathrm{E}-03$ & $2.5 \mathrm{E}-02$ & $\mathbf{3}$ & $3.5 \mathrm{E}-02$ & $1.1 \mathrm{E}-01$ & $\mathbf{1 1}$ & $1.5 \mathrm{E}-03$ & $4.8 \mathrm{E}-03$ \\
\hline $\mathbf{1 9}$ & $5.5 \mathrm{E}-03$ & $1.8 \mathrm{E}-02$ & & & & $\mathbf{1 9}$ & $1.1 \mathrm{E}-03$ & $3.5 \mathrm{E}-03$ \\
\hline $\mathbf{2 0}$ & $5.4 \mathrm{E}-03$ & $1.8 \mathrm{E}-02$ & & & & $\mathbf{2 0}$ & $1.0 \mathrm{E}-03$ & $3.4 \mathrm{E}-03$ \\
\hline $\mathbf{2 1}$ & $1.1 \mathrm{E}-02$ & $3.6 \mathrm{E}-02$ & & & & $\mathbf{2 1}$ & $2.2 \mathrm{E}-03$ & $7.1 \mathrm{E}-03$ \\
\hline $\mathbf{2 2}$ & $1.6 \mathrm{E}-02$ & $5.2 \mathrm{E}-02$ & & & & $\mathbf{2 2}$ & $3.1 \mathrm{E}-03$ & $1.0 \mathrm{E}-02$ \\
\hline
\end{tabular}

The model of ship traffic in Batam Island accommodate the international waterway which mainly is used by international fleet with relative big size of merchant ship, and crossing waterway which is used mainly by high speed passenger vessel. Based on the data, the crossing shipping lane connects some ports around Batam Island to Singapore and Malaysia, such as Batam Center, Sekupang, Batu Ampar, Tanjung Balai Karimun, Nongsa, Teluk Senimba, Tanjung Uncang, Teluk Lobam, Harbor Bay, Tanah Merah, Harbourfront, Pasir Gudang. The traffic between these ports enter crosses the TSS in Way Point 1 and 2. While the ship traffic influences by Port of Tanjung Pinang is modeled using 5 LEGs (LEG 11, 19, 20, 21 and 22) and 1 Way Point (WP 3). The traffic from/to Port of Tanjung Pinang is comprised of merchant ship and fast patrol boat which both uses international lane of TSS as well as crossing the lane. The traffic model in Port of Dumai comprises of 7 LEGs (LEG 12, 13, 14, 15, 16, 17 and 18) and 2 Way Point (WP 4 and 5). The traffic around Dumai Port is dominated by Product and Crude oil, Gas tanker, chemical tanker, general cargo ship, passenger ship 
and bulk carrier. The IWRAP model would be better when further compared by other method as comparison of modeling result.

This paper shows the frequency of ship collision for traffic data in 2016 and estimates the future collision frequency caused by the port development in Batam, Dumai and Tanjung Pinang. These port development is estimated to annually increases the ship traffic density by $3 \%$ for 20 years. The result of IWRAP Mk2 ship traffic model for frequency of ship collision in SOMS which is influenced by the ship traffic in Batam Port, Port of Dumai and Port of Tanjung Pinang are shown in Table 1, Table 2 and Table 3 respectively. Table 1 shows that in around Batam, LEG 2 and Way Point 1 have the highest frequency of overtaking and crossing collision respectively. This is because in this location, there are high density of ship for both international voyage and the crossing lane. Table 2 shows that LEG 16 and Way Point 4 have the highest frequency of overtaking and crossing collision since this is the area where the international shipping lane meets the crossing vessel and the ship from port of Dumai.

Table 4: Total Collision Frequency of Ship Traffic in SOMS Influenced by Port of Batam, Dumai and Tanjung Pinang

\begin{tabular}{|c|c|c|c|c|c|c|c|c|}
\hline \multirow{2}{*}{ Tipe } & \multicolumn{2}{|c|}{ Batam } & \multicolumn{2}{c|}{ Dumai } & \multicolumn{2}{c|}{ Tanjung Pinang } & \multicolumn{2}{c|}{ Total Frequency } \\
\cline { 2 - 10 } & Now & Future & Now & Future & Now & Future & Now & Future \\
\hline Head on & 0.001186 & 0.003522 & 0.025972 & 0.02574 & 0.045554 & 0.148563 & 0.07271 & 0.17783 \\
\hline Crossing & 0.114938 & 0.365826 & 0.007763 & 0.08476 & 0.035109 & 0.114446 & 0.15781 & 0.56504 \\
\hline Overtaking & 0.08845 & 0.28886 & 0.275638 & 0.89895 & 0.007815 & 0.028895 & 0.37190 & 1.21671 \\
\hline
\end{tabular}

Table 3 shows that LEG 22 has the highest frequency of head on collision which is caused by the high density of ship inbound and outbound to/from Port of Tanjung Pinang. The value of frequency for head on collision is less than overtaking and crossing collision. It is caused by the event of head on collision has been reduced by TSS which separate the two opposite direction of shipping route. Table 1 and Table 2 shows that the value of head on collision is very low while Table 3 shows that the value of head on collision frequency in bigger than overtaking collision. It is because there is no separation zone/line in the traffic lane which are modelled which makes the probability of head on collision becomes higher. The total result of model calculation in IWRAP Mk2 for the current and future frequency of ship collision is shown in Table 4. The result for head on, overtaking and crossing collision are $0.07271,0.3719$, and 0.15781 respectively for the current year, while for the future 20 years are $0.17783,1.21671$ and 0.56504 respectively. It is clearly found that the estimation of ship collision frequency in the future 20 years is higher than the current year caused by the increasing of ship traffic density caused by Indonesian port development around SOMS. Further research should accommodate the comparison of the result of the current IWRAP model with other method in order to prove the result of this study.

\section{Conclusion}

This paper has conducted a vessel traffic modelling for Strait of Malacca and Singapore (SOMS) influenced by Indonesian port development including Port of Dumai, Port of Tanjung Pinang and Port in Batam Island. The IALA Waterway Risk Assessment Program (IWRAP Mk 2) is utilized in the modelling process. The data of ship traffic in these ports during year 2016 is used as input for IWRAP and estimated there is annual $3 \%$ increases of ship traffic caused by port development. The 
result shows that the highest total frequency of ship collision in Batam, Dumai and Tanjung Pinang are crossing, overtaking and head on collision respectively, with their value (current and future) are 0.114938, 0.365826; 0.275638, 0.898957; and 0.045554; 0.148563 respectively. It is clearly shown that the frequency of ship collision is significantly increases for future ship traffic. The result of this study is very important for the three literal country (Indonesia, Singapore and Malaysia) for taking any decision and effort for preventing the future collision around SOMS because based on the modelling in this study, some type of collision appear dominant with higher value of collision frequency than other type of collision. It is important to know so as become a recommendation to reduce the ship collision frequency, such as applying regulation of maximum ship speed and widening the shipping channel which needs further research to know how significant the effect on the reduction of collision frequency to increase the ship traffic safety in this area.

\section{Acknowledgement}

The authors acknowledge to the Laboratory of Reliability, Availability, Management and Safety (RAMS), Dept. of Marine Engineering - Institut Teknologi Sepuluh Nopember (ITS) for supporting the technical issue regarding for this study.

\section{References}

[1]X. Qu, and Q. Meng, "Development and applications of a simulation model for vessels in the Singapore Straits”, Expert Systems with Applications, vol. 39, pp. 8430-8438, 2012.

[2]MPA Singapore, “MPA Annual Report 2014”, Singapore, 2014

[3]L. Zhang, Q. Meng, T.F. Fwa, “Big AIS data based spatial-temporal analyses of ship traffic in Singapore port waters”, Transportation Research, 2017

[4]X. Qua, Q. Meng, L. Suyi, "Ship collision risk assessment for the Singapore Strait”, Accident Analysis and Prevention, vol. 43, pp. 2030-2036, 2011

[5]IWRAP, http://www.iala-aism.org/wiki/iwrap/index.php/Main_Page, visited on 7 February 2018

[6] Y. Fujii, H. Yamanouchi, N. Mizuki, On the fundamentals of marine traffic control. Part1: probabilities of collision and evasive actions. Electronic Navigation Research Institute Papers, vol. 2, pp. 1-16, 1970

[7]Y. Fujii, H. Yamanouchi, N. Mizuki, "Some factors affecting the frequency of accidents in marine traffic. II: The probability of stranding. III: The effect of darkness on the probability of stranding”, Journal of Navigation vol. 27, 1974

[8]T. Mac Duff, “The probability of vessel collisions”, Ocean Industry, 144-8, 1974

[9]J. Ylitalo, "Modelling Marine Accident Frequency", Master Theses at School of Science and Technology, Aalto University, 2010

[10]PT. Pedersen. “Collision and grounding mechanics”, Proceedings of WEMT'95. The Danish Society of Naval Architects and Marine Engineers, pp. 461-74, 1995

[11]TG. Fowler, E. Sørgrad, “Modeling ship transportation risk Risk Analysis”; vol. 20(2), pp. 225-44 2000

[12]Sofartsstyrelsen, "Risk analysis of sea traffic in the area around Bornholm", Technical report, COWI, Kongens Lyngby, 2008

[13]F. Kaneko, "Methods for probabilistic safety assessments of ships”, Journal of Marine Science and Technology,vol. 7, pp. 1-16, 2002

[14]J. Montewka, F. Goerlandt, P. Kujala, “Determination of collision criteria and causation factors appropriate to a model for estimating the probability of maritime accidents”, Ocean Engineering, vol. 40, pp. 50-61

[15]J. Montewka, T. Hinz, P. Kujala, J. Matusiak, "Probability modelling of vessel collisions", Reliability Engineering and System Safety, vol. 95, pp. 573-89, 2010

[16]P. Friis-Hansen., "Basic Modelling Principles for Prediction of Collision and Grounding Frequencies”, Technical University of Denmark, 2008

[17]IALA, “IWRAP - Theory”, http://www.iala-aism.org/wiki/iwrap/index. php / Theory, visited at 11 February 11, 2018

[18]Density Maps, www.marinetraffic.com, visited at December 5, 2017 